Transport and Communications Science Journal, Vol. 72, Issue 7 (09/2021), 778-788

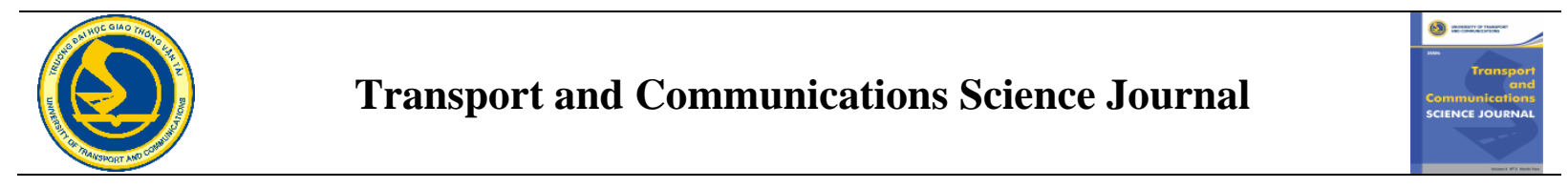

\title{
MODELLING SCHOOL TRAVEL MODE CHOICE - THE CASE OF HANOI, VIETNAM
}

\author{
Minh Hieu Nguyen* \\ University of Transport and Communications, No 3 Cau Giay Street, Hanoi, Vietnam
}

\begin{abstract}
ARTICLE INFO
TYPE: Research Article

Received: 03/10/2020

Revised: 04/07/2021

Accepted: 11/07/2021

Published online: 15/09/2021

https://doi.org/10.47869/tcsj.72.7.1

* Corresponding author

Email: hieunm@utc.edu.vn
\end{abstract}

\begin{abstract}
The COVID-19 outbreak has resulted in adopting massively social distancing measures to tame the human-to-human transmission of the new coronavirus and protect public health. These intervention policies have caused changes in travel behavior, thereby expressing a need to update profiles of factors associated with mode choice. To respond to this research gap in part, this current study aims to model children's mode decisions for school trips in the post-pandemic time in Hanoi. As regards mode usage, cycling is the main mode of active transport with a share at $23.3 \%$, doubling the rate of $11 \%$ for walking. The dominant mode of traveling to school is the motorized modes (i.e., cars and motorcycles) with a proportion of $60 \%$, meanwhile, school buses account for only $6.2 \%$. As regards the determinants, when growing up, children tend to shift from being driven to traveling actively. The availability of cars increases the likelihood of using other modes compared to cycling. An opposite association is seen for the availability of bicycles. The flexibility in terms of a mother's job is involved in a higher possibility of being driven for a child. A home-school distance less than 1 $\mathrm{km}$ is more suitable for walking compared to cycling; however, an inverse relationship is witnessed for a distance between 1 and $2 \mathrm{~km}$. A distance over $2 \mathrm{~km}$ is more appropriate for motorized modes and school buses. To promote active transport to school, children's travel demand should be taken transport planning into consideration. Developing cycling and walking facilities is essential, especially in urban districts. Additionally, limiting the use of private motorized modes would be useful.
\end{abstract}

Keywords: COVID-19, active transport, cycling, Hanoi, school closure, mode choice. 


\section{INTRODUCTION}

A growing trend seen over the world is the stable decrease in walking and cycling (i.e., active transport) in tandem with the rapidly increasing use of motorized modes to go to school for children [1-4]. It is important to note that active transport to school has great benefits for both children and societies. Particularly, active commuting is a primary source of physical activity which helps to prevent cardiovascular and obesity for children [5]. Along with health benefits, active transport can contribute to forming a sustainable and green habit in travelling. Childhood is the period of life when travel habits and attitudes towards environment are established [6]. Such routines and views then are relatively stable throughout the rest of life. Walking and cycling can enable alleviation of traffic congestion and safer environment, especially around schools, thanks to reducing the number of motorized trips [7]. For preventing the downward trend in active travel to school and recover the share of this mode, it is essential to recognize the determinants of children's mode choice for school trips. Knowledge about factors and how they affect the school travel decision enable policy-makers to issue pertinent policy measures to encourage active transport engagement and discourage the use of motorized modes.

The extant literature has witnessed two main groups of studies on active transport to school. The first is to explore factors associated with whether children travel actively to school, such as [8-11]. The second considers a broader scope with multiple travel modes included [12-14]. The results of the second group would be more informative because walking and cycling are usually included separately rather than grouped into only one mode (i.e., active transport). Similarly, competing modes over active transport are considered in more details with cars and school buses instead of only one type (i.e., motorized/passive/nonactive mode). However, the inclusion of many modes would lead to more difficulty in interpreting findings. Both of research categories have provided huge understandings of factors associated with the use of travel modes, especially walking and cycling, on the way to school under normal circumstances.

The COVID-19 outbreak first occurring in Wuhan (China) in December 2019 has rapidly disseminated in a host of countries over the world, leading the World Health Organization to declare a public health emergency of international concern, the highest level of alarm in January. Afterward the outbreak was announced officially as a pandemic on 11 March 2020 [15]. To tame the risk of human-to-human transmission of the new coronavirus causing COVID-19, numerous nations have adopted unprecedented measures, such as social distancing, quarantine, and lockdown. These interventions, on the one hand, have crucial and positive effects on protecting public health but, on the other hand, they have made substantial changes in how people travel [16]. A wealth of children, who are one of vulnerable groups in the battle against the COVID-19 [17], has suffered from a long stay at home due to the closure of schools. According to [18], more than 1 billion students have been out of school due to the nationwide closure of 105 among 134 countries. Because of detrimental impacts of the health crisis and the long school closures, children possibly change their transportation mode selections when making a return to school. Therefore, it is necessary to update understandings of factors associated with students' mode choice in the post-pandemic period.

Vietnam is a typical example of controlling the pandemic successfully [19] thanks to the active and soon preparation of the government for responding the occurrence and spread of the coronavirus [20,21]. After one month of social distancing with no confirmed cases detected in the public, the lifting of school closures was introduced at the end of April, 
allowing students to return to school. Compared to other countries, Vietnam is one of the first countries re-opening schools [22]. This situation facilitates an implementation of studies of how children travel to school in the post-pandemic time. There, to the best of my knowledge, have been two previous studies focusing on children active transport, both of which were carried out in Ho Chi Minh City [23, 24]. The authors of [23] provide updated and interesting findings on factors associated with daily active transport rather than walking or cycling to school. Whereas the authors of [24] report determinants of commuting actively to school using longitudinal data. Nevertheless, with a decade gone by, the status of factors and mode use would change significantly, especially under the impacts of the COVID-19 crisis. Because of all above-mentioned reasons, this current study chooses Hanoi as the research venue to investigate factors affecting the decisions on the modes used by children aged 9-15 years old to go to school that re-opened after the social distancing time.

The rest of this paper is structured as follows. Section 2 reviews earlier studies on factors associated with mode choice of children for home-school trips. Next, the process of recruitment and the creation of the questionnaire are presented. Also in this part, multinomial logit regression modelling is described with details of variables used and how to interpret estimated coefficients. The following section presents results and discussion about them in comparison with previous knowledge of determinants of children's mode decision. Finally, conclusions and limitations are offered to show future research directions.

\section{LITERATURE REVIEW}

Numerous researchers have quantitatively investigated various factors influencing the school trip mode choices [12-14], [25,26]. Age and gender are the two socio-demographics most frequently included. Most studies report that age has a positive relationship with cycling/walking and an inverse one with the use of cars. An example is indicated in [25] wherein an increase in one year results in a $0.4 \%$ increase in the likelihood of walking and a relative $1.4 \%$ decrease in the probability of being driven. Similar results are documented in $[14,25]$. Interestingly, an older child is more likely to choose school bus in comparison with a younger counterpart [26]. Age is not a significant variable for predicting the choice of walking compared to being driven and compared to utilizing a family vehicle in [12]. In comparison with females, males are more likely to walk or cycle to school in comparison with being chauffeured [13]. Regarding active transport modes, with the reference being females, males are more inclined to cycle against walking [12]. Interesting, males living within $3 \mathrm{~km}$ of school in Beijing are more inclined to cycle over all of other modes (walk, public transport, and car) compared to females [25]. The author of [26] does not find a significant role of gender in the choice of walking.

Distance is widely accepted to have the strongest effects on the mode decision, especially for the use of private motorized vehicles and active modes. According to [26], a 10\% increase in walk travel time results in a $7.5 \%$ decrease in walking's mode share. However, the same increase in auto travel time leads to only a $0.1 \%$ increase in the possibility of walking. A longer distance is involved in less likelihood of walking [12,14]. Notably, children living within 2 miles of their schools are more likely to walk or cycle but less likely to commute by school bus [13]. Nevertheless, a contradictory finding is offered in [25] wherein on the distance between 3-10 km against greater than $10 \mathrm{~km}$, bicycles are more likely to be chosen compared to public transport. 
Children in households are an important factor since the availability/number of children affects significantly the parental escorting behaviour [6]. A child having siblings tend to walk and is less likely to use auto [26].

Ownership of vehicle types in households is well demonstrated as determinants of mode choice. Car is the main mode in developed countries $[13,14,26]$ and popular in developing countries $[12,25]$; therefore, it is usually considered. The higher number of cars make children more likely to be driven $[12,13,25]$ and less likely to utilize school bus $[14,25]$ and walk [26]. The availability of bicycle is positively associated with the possibility of cycling but negative with being escorted by motorized modes [12]. The same results are seen for the presence of motorcycle in [12].

Mothers take main roles in chauffeuring children [8]; therefore, the availability of female parents is a predictor of how children travel to school. If a mother is a full-time worker, her child is less likely to be walked by her [14]. The authors of [13] find that a child whose mother has a flexible work start time is more likely to travel by bus against being driven.

The residential areas may have significant effects on the choice of travel modes to school. In the US, children in a rural area are more likely to take a school bus compared to peers in an urban region $[13,14]$. More urbanized area is more suitable for active modes because of shorter distances between home and points of interests and more built environment for walking and cycling [7].

\section{DATA AND METHOD}

\subsection{Data collection}

The area of this study is Hanoi that is the capital of Vietnam, an emerging country in the Global South [27]. Likewise other cities of other developing countries, such as Jakarta, Indonesia or Bangkok, Thailand [28], Hanoi has been confronting big challenges related to urban transport like severe traffic congestion and serious pollution [29]. The reasons for these issues are the uncontrolled growth in motorcycle ownership and the limited capacity of public transport system with the only presence of conventional buses [30].

To conduct this research, a structured questionnaire was made with five main parts. The first section included a cover letter introducing the aim and scope of this survey. Single-parent households were out of consideration. In the second part, the profile of households (e.g., monthly income, ownership of vehicle types) was asked. The third section requested background information of parents, such as type of working time, working flexibility, and educational level. In the following section, characteristics of children and their schools were gathered. Specifically, age and gender of children together with home-school distance, type and area of school were asked. The last section included questions with respect to travel modes from and to school before and after the COVID-19 time.

The school closure in Hanoi was removed since 4 and 11 May 2020 for secondary and primary degrees, respectively. The time of survey was determined within two weeks from 18 to 29 May 2020. To implement recruitment, the author requested the support from some schools in both urban and non-urban areas. Urban areas refer to districts of Hanoi while nonurban areas refer to the rest. Only one non-urban school (at both primary and secondary grades) accepted to participate in the survey. Teachers of classes were requested to distribute printed questionnaires to children to bring them to their parents. The completion of these forms was optional. Subsequently, completed questionnaires were re-collected by teachers 
who then gave them to the author on 29 May. Also during this time, to collect data of children studying in urban districts, an online version of the questionnaire was created using Google Forms. Afterwards, the link of this survey was sent to lecturers at University of Transport and Communications with a request for further sharing this link with their friends and relatives who are living in urban districts. After the two weeks of survey, 506 households provided answers; however, 25 of them were excluded because they were living outside Hanoi. Consequently, the samples encompassed 481 households reporting data of 736 children aged 6-15 years old. This study only considers children who were between 9 and 15 years old and travelled by either walking or cycling or school bus or motorcycle or car. Therefore, the final data included responses of $420,47 \%$ of which were collected online.

Table 1. Breakdown of the samples $(\mathrm{N}=420)$.

\begin{tabular}{|c|c|c|c|c|}
\hline Variable & Value & Frequency & Percent & Cumulative \\
\hline \multirow{2}{*}{ Gender } & Male & 218 & 51.9 & 51.9 \\
\hline & Female & 202 & 48.1 & 100.0 \\
\hline \multirow{7}{*}{ Age } & 9 & 70 & 16.7 & 16.7 \\
\hline & 10 & 64 & 15.2 & 31.9 \\
\hline & 11 & 48 & 11.4 & 43.3 \\
\hline & 12 & 68 & 16.2 & 59.5 \\
\hline & 13 & 64 & 15.2 & 74.8 \\
\hline & 14 & 50 & 11.9 & 86.7 \\
\hline & 15 & 56 & 13.3 & 100.0 \\
\hline \multirow{2}{*}{ Firstborn child } & yes & 247 & 58.8 & 58.8 \\
\hline & no & 173 & 41.2 & 100.0 \\
\hline \multirow{2}{*}{ Car ownership } & zero car & 258 & 61.4 & 61.4 \\
\hline & $>=1 \mathrm{cars}$ & 162 & 38.6 & 100.0 \\
\hline \multirow{2}{*}{$\begin{array}{l}\text { Motorcycle } \\
\text { ownership }\end{array}$} & zero or one motorcycle & 100 & 23.8 & 23.8 \\
\hline & $>=2$ motorcycles & 320 & 76.2 & 100.0 \\
\hline \multirow{2}{*}{ Bicycle ownership } & zero bicycle & 168 & 40.0 & 40.0 \\
\hline & $>=1$ bicycle & 252 & 60.0 & 100.0 \\
\hline \multirow{2}{*}{$\begin{array}{l}\text { Mother's working } \\
\text { flexibility }\end{array}$} & yes & 218 & 51.9 & 51.9 \\
\hline & no & 202 & 48.1 & 100.0 \\
\hline \multirow{2}{*}{ School area } & non-urban area & 210 & 50.0 & 50.0 \\
\hline & urban area & 210 & 50.0 & 100.0 \\
\hline \multirow{3}{*}{$\begin{array}{l}\text { Home-school } \\
\text { distance }\end{array}$} & under $1000 \mathrm{~m}$ & 59 & 14.1 & 14.1 \\
\hline & 1000-under $2000 \mathrm{~m}$ & 141 & 33.6 & 47.6 \\
\hline & $>=2000 \mathrm{~m}$ & 220 & 52.4 & 100.0 \\
\hline \multirow{4}{*}{ Travel mode } & walking & 46 & 11.0 & 11.0 \\
\hline & cycling & 98 & 23.3 & 34.3 \\
\hline & motorcycle/car & 250 & 59.5 & 93.8 \\
\hline & school bus & 26 & 6.2 & 100.0 \\
\hline
\end{tabular}

As can be seen in Table 1, the samples were nearly balanced in terms of gender with slightly more males. There was insignificantly age-based bias because the shares of children according to age were comparable, with the minimum and maximum proportions being $11.4 \%$ for the age of 11 and $16.7 \%$ for the age of 9 , respectively. The greater number of children (247) were the firstborn children while $173(41.2 \%)$ were those with younger siblings. Of 420, $38.6 \%$ came from households having at least one car. The vast majority of children $(76.2 \%)$ were living in households with at least two motorcycles. This was in line with the fact that motorcycles are the main travel mode in Hanoi. Interestingly, $60 \%$ of those surveyed had 
bicycles in their families. Approximately 52\% mothers of samples had working flexibility. The perfectly balanced rates of children according to areas of schools were seen. Only $14.1 \%$ of students were living far less than $1000 \mathrm{~m}$ from school meanwhile distances equal to or over $2000 \mathrm{~m}$ accounted for the high rate of $52.4 \%$.

As regards travel mode use, walking made up about $11 \%$ while the share of cycling was $23.3 \%$, thereby leading the rate of active transport to school to be $34.3 \%$. This active transport proportion is close to that in Hong Kong [9] but far below that in Ghana [10]. Nearly 60\% of children were chauffeured by either car or motorcycle. By contrast, the school bus service was utilized by the smallest number of children (6.2\%).

\subsection{Method}

The method most frequently used in the literature is binary logit regression [9-11, 31]. Its advantages are easily to estimate and interpret results. Nevertheless, binary logit modelling only considers whether a pupil performs active transport; therefore, it is inappropriate for a study regarding more than two travel options.

This study chose multinomial logistic regression (MNL) to model mode choices of children on the way to school because this has been deployed by previous authors [12-14], [26]. Specifically, logit models are discrete choice models based on the random utility theory wherein each decision-maker has a unique utility function and the alternative having the maximum utility is more attractive over all of the remainder of alternatives in the choice set [32]. The likelihood maximization technique was used to estimate the MNL model for mode choice.

The dependent variable was the mode that a child used to go to school. This variable had four values corresponding to four modes, including walking, cycling, car/motorcycle, and school bus. This study put a heavier focus on determinants of actively traveling to school therefore walking and cycling were candidates for the reference category. Because cycling is the main mode of active transport to school in Hanoi, similar to [25], cycling was chosen as the reference category.

The estimated coefficient of a predictor variable in a MNL framework can be interpreted by two ways, depending upon the type of this predictor. If a predictor is a continuous variable, a one-unit increase in this variable is associated with a coefficient-levelled change in the relative log odds of being a considered choice (e.g., school bus) vs. the base outcome (i.e., cycling). If a predictor is not a continuous variable, a reference value was set up for this variable. Subsequently, the coefficient is a coefficient-levelled change in the relative log odds of being a considered choice (e.g., school bus) vs. the base outcome (i.e., cycling) if the value of the considered predictor variable shifts from the reference value to another level.

A potential issue for a regression model is multicollinearity that causes unstable estimations of $\mathrm{p}$-values, thereby leading to misunderstanding of association between a dependent variable with predictors. To detect the multicollinearity problem, the computation of variance inflation factors (VIFs) was undertaken. All of statistical analyses were conducted using Stata 15.0.

\section{RESULTS AND DISCUSSIONS}

The output of model presented in Table 2 indicates the likelihood ratio chi-square (288.30) has a p-value $<0.0000$, which demonstrates that the model with predictors fits significantly better than the empty model (i.e., with intercept only). This result is well 
supported by the value of Pseudo R2 (0.3229), which is the change in terms of log-likelihood from the empty model to the present model. Theoretically, a higher level of Pseudo R2 is involved in a better model. Table 3 providing the results of Collinearity diagnostics shows that all of predictor variables have VIFs by far smaller than 4; therefore, such variables can be safely kept in the MNL without a concern about the risk of multicollinearity [33]. All of the above-mentioned results of tests demonstrate that the MNL can give reliable estimations of determinants of children's mode choice for trips to school.

Table 2. The results of multinomial logit model.

\begin{tabular}{|c|c|c|c|c|c|c|c|}
\hline & \multirow{2}{*}{ Variable } & \multicolumn{2}{|c|}{ Walking } & \multicolumn{2}{|c|}{ Car/Motorcycle } & \multicolumn{2}{|c|}{ School bus } \\
\hline & & Coef & $\mathrm{P}>|\mathrm{z}|$ & Coef & $\mathrm{P}>|\mathrm{z}|$ & Coef & $\mathrm{P}>|\mathrm{z}|$ \\
\hline \multirow[t]{2}{*}{1} & Gender $($ ref $=$ male $)$ & & & & & & \\
\hline & Female & 0.259 & 0.595 & -0.061 & 0.840 & 0.987 & 0.103 \\
\hline 2 & Age & -0.124 & 0.266 & -0.340 & 0.000 & -0.629 & 0.000 \\
\hline \multirow[t]{2}{*}{3} & Firstborn child $(r e f=$ Yes $)$ & & & & & & \\
\hline & No & -1.391 & 0.009 & -0.256 & 0.403 & 0.936 & 0.113 \\
\hline \multirow[t]{2}{*}{4} & Car ownership $($ ref $=$ zero car $)$ & & & & & & \\
\hline & $>=1$ cars & 1.443 & 0.010 & 1.059 & 0.006 & 2.519 & 0.000 \\
\hline \multirow[t]{2}{*}{5} & $\begin{array}{l}\text { Motorcycle ownership } \\
\text { (ref=zero or one motorcycle) }\end{array}$ & & & & & & \\
\hline & $>=2$ motorcycles & -0.120 & 0.843 & 0.552 & 0.185 & 0.564 & 0.394 \\
\hline \multirow[t]{2}{*}{6} & Bicycle ownership $($ ref=zero bicycle $)$ & & & & & & \\
\hline & $>=1$ bicycle & -3.532 & 0.000 & -2.187 & 0.000 & -2.776 & 0.000 \\
\hline \multirow[t]{2}{*}{7} & Mother's working flexibility $(r e f=n o)$ & & & & & & \\
\hline & Yes & 0.138 & 0.772 & 0.903 & 0.004 & 0.432 & 0.460 \\
\hline \multirow[t]{2}{*}{8} & School area $($ ref=non-urban area $)$ & & & & & & \\
\hline & Urban area & 1.735 & 0.000 & 1.576 & 0.000 & 2.541 & 0.001 \\
\hline \multirow[t]{9}{*}{9} & $\begin{array}{l}\text { Home-school distance } \\
(\text { ref }=1000-\text { under } 2000 \mathrm{~m})\end{array}$ & & & & & & \\
\hline & under $1000 \mathrm{~m}$ & 1.711 & 0.003 & -0.841 & 0.072 & -13.133 & 0.982 \\
\hline & $>=2000 \mathrm{~m}$ & -0.823 & 0.151 & 0.852 & 0.010 & 3.053 & 0.001 \\
\hline & cons & 1.918 & 0.248 & 4.777 & 0.000 & 1.596 & 0.433 \\
\hline & Number of observations & \multicolumn{6}{|c|}{420} \\
\hline & LR chi2 (30) & \multicolumn{6}{|c|}{288.30} \\
\hline & Prob > chi2 & \multicolumn{6}{|c|}{0.0000} \\
\hline & Pseudo R2 & \multicolumn{6}{|c|}{0.3229} \\
\hline & Log likelihood & \multirow{2}{*}{\multicolumn{6}{|c|}{-302.2359}} \\
\hline & outcome $=$ cycling & & & & & & \\
\hline
\end{tabular}

Table 2 presents the findings from the mode choice model, in which factors show how they change the likelihood of walking, being driven by motorcycle or car, taking school bus compared to cycling.

Unlike the previous studies $[12,13,25]$, gender here is not a predictor. Age is not a significant factor as regards choosing walking; however, has negative associations with the probability of using motorized modes (i.e., car or motorcycle) and school bus. This can be explained that children become more independent when growing up. As a result, they tend to shift from being transported to implement active transport like cycling or walking [26].

A child living with at least a younger sibling is less likely to walk. The availability of car is an important predictor of mode decision because it increases the probability of using 
walking, motorized modes, and school bus compared to cycling. While the positive relationship between the presence of car and the likelihood of being driven is easily understandable, the associations between the car possession and the possibilities of walking and utilizing school bus may come from the choice of school types. In fact, families that are affordable to buy cars tend to send their children to high-quality schools such as private or international ones, many of which offer school buses. Besides, many families may live in apartments of complex centres at which schools are located like Times City of Vingroup (Vietnam). The possession of motorcycles do not have any significant effects on the mode choice. Unsurprisingly, a child from a household with at least one bicycle is more likely to cycle against other modes. This can be interpreted that bicycles in Hanoi are mainly used for children on the road to school but rarely for adults on the way to workplace.

With a working flexibility, a mother can have a favourable condition to transport her child. To put it another way, this child is more likely to use motorized modes to go to school.

Children living in an urban area are more likely to walk, use school bus, and motorized modes compared to those living in a suburban or rural area. Such findings are inconsistent with those reported in $[13,14]$. The first reason would be that facilities for walking (e.g., sidewalk) in urban districts are increasingly constructed and well maintained [7]. Furthermore, the distances between places there are much smaller, which is more appropriate for walking. Roads in the centre of Hanoi is much congested with mixed traffic, likely leading cycling to be relatively risky and inconvenient. Hence, parents are more inclined to drive their children or hire school bus for them. The less likelihood of using school bus in the non-urban area stem from the underdevelopment of this service there.

As regards home-school distance, the finding of this present study supports earlier conclusions [25, 26]. A distance less than $1 \mathrm{~km}$ is suited for walking, demonstrating a higher possibility of walking over cycling. Whereas a distance over $2 \mathrm{~km}$ seems more appropriate for travelling by school bus or motorized modes.

Table 3. Collinearity diagnostics.

\begin{tabular}{|l|c|c|c|c|}
\hline \multicolumn{1}{|c|}{ Variable } & VIF & VIF $^{\mathbf{2}}$ & Tolerance & R-Squared \\
\hline Firstborn child & 1.09 & 1.04 & 0.9188 & 0.0812 \\
\hline Gender & 1.09 & 1.05 & 0.9156 & 0.0844 \\
\hline Age & 1.05 & 1.02 & 0.9567 & 0.0433 \\
\hline Car ownership & 1.33 & 1.16 & 0.7496 & 0.2504 \\
\hline Motorcycle ownership & 1.27 & 1.13 & 0.7874 & 0.2126 \\
\hline Bicycle ownership & 1.07 & 1.03 & 0.9374 & 0.0626 \\
\hline Mother's working flexibility & 1.06 & 1.03 & 0.9462 & 0.0538 \\
\hline School area & 1.15 & 1.07 & 0.8710 & 0.1290 \\
\hline Home-school distance & 1.03 & 1.02 & 0.9686 & 0.0314 \\
\hline Mean VIF & 1.13 & & & \\
\hline
\end{tabular}

The analysed-above findings suggest some approaches to improve a sustainable travel habit on the way to school. First, it would be vital to regard children's travel when making transport planning. Specifically, more school bus services should be introduced with an enhanced quality to attract and serve more students. Currently, school bus trips are offered by individual schools; therefore, to promote sustainably this mode, the local government may ask and aid bus operators (e.g., Transerco) to provide citywide school buses besides conventional 
bus routes. Developing facilities dedicated to walking and cycling is essential because it can improve safety for children when engaging in active transport. This way is the key as the characteristics of traffic flows in Hanoi are mixed and congested with high risks of collisions. The construction of more active transport-specific environment would be more suitable for urban districts while the promotion of school buses would be more prioritized in non-urban areas.

Cycling was the most popular mode in Hanoi; however, it accounts for a marginal share now [30]. Because children tend to copy the behaviours of their parents, if the habit of cycling is recovered in Hanoi, it will be expected to encourage more active transport for students.

Ownership of motorized modes is obviously an issue against active transport. The evidence from Hanoi emphasizes the inverse association between the availability of cars and the likelihood of cycling. Unfortunately, according to [34], the growth in car use is an alarming challenge for Hanoi in the short and medium terms. Therefore, measures to limit the use and/or ownership of cars are necessary to enhance active transport. The possession of motorcycles, although being not a significant factor in this research, would be a barrier to commute actively to school. The insignificant role of this variable may result from the fact that almost all households in Hanoi have motorcycles; therefore, the number of this vehicle in households do not affect significantly the choice other modes. Limiting the use of motorcycles would be a way useful for boosting the use of either active transport or school bus.

\section{CONCLUSIONS}

The spread of COVID-19 has made the local government close schools to protect the health of children, thereby probably affecting how children travel to school in the postpandemic period. Using data of 420 children collected in Hanoi, Vietnam after social distancing period, this study explores factors associated with the mode choice for school trips. The main findings are as follows. Active transport makes up $34.3 \%$ with the share of cycling being $23.3 \%$. Motorized modes are used the most with the share of nearly $60 \%$. The age has a positive association with the likelihood of performing active transport but negative with being driven by motorized modes. The availability of car is a deterrent of travelling actively. Children in urban areas are more likely to walk, use car, and take school bus compared to cycling. The distance ideal for walking and cycling would be under $1 \mathrm{~km}$ and $2 \mathrm{~km}$, respectively. To form and improve a sustainable travel habit, it is necessary to consider children's travel demand in creating transport planning and recover the use of bicycles in daily life of citizens in Hanoi. Limiting the possession and the utilization of motorized private modes is essential. In parallel, enhancing school bus services is necessary.

This paper is subject to two limitations. First, the recruitment process was carried out using a non-probabilistic snowball sampling technique; hence, the generalizability of findings would be weak more or less. Second, the sample size would be small to some extent. Besides, many attitudinal factors, which previously are found to be important factors of mode choice, such as parental attitudes towards safety and security, are not considered in this research. Such shortcomings should be taken into consideration and addressed in the following studies. This work presents initial results of the determinants of school trip mode decision after a social distancing time; yet, the unprecedented evolution of the pandemic requires us to keep monitoring and updating understanding of how students travel to school and influential factors in various countries over the world. 
Transport and Communications Science Journal, Vol. 72, Issue 7 (09/2021), 778-788

\section{ACKNOWLEDGEMENTS}

This research is funded by University of Transport and Communications (UTC) under grant number T2021-KT-002. The author would like to give many thanks to Dr. Dorina Pojani at University of Queensland and MSc. Thanh Tung Ha along with Prof. Thanh Chuong Nguyen at UTC for their kind support regarding the creation of the questionnaire and the recruitment process. However, this work is an independent work of the author and he takes responsibility for any errors left.

\section{REFERENCES}

[1]. A. Fyhri et al., Children's active travel and independent mobility in four countries: Development, social contributing trends and measures, Transport Policy, 18 (2011) 703-710. https://doi.org/10.1016/j.tranpol.2011.01.005

[2]. L. Grize et al., Trend in active transportation to school among Swiss school children and its associated factors: three cross-sectional surveys 1994, 2000 and 2005, Int J Behav Nutr Phys Act, 7 (2010) 28. https://doi.org/10.1186/1479-5868-7-28

[3]. K. Witten et al., New Zealand parents' understandings of the intergenerational decline in children's independent outdoor play and active travel, Children's Geographies, 11 (2013) 215-229. https://doi.org/10.1080/14733285.2013.779839

[4]. N. C. McDonald, Active transportation to school: trends among U.S. schoolchildren, 1969-2001, Am J Prev Med, 32 (2007) 509-516. https://doi.org/10.1016/j.amepre.2007.02.022

[5]. G. E. J. Faulkner et al., Active school transport, physical activity levels and body weight of children and youth: A systematic review, Preventive Medicine, 48 (2009) 3-8. https://doi.org/10.1016/j.ypmed.2008.10.017

[6]. J. Scheiner, School trips in Germany: Gendered escorting practices, Transportation Research Part A: Policy and Practice, 94 (2016) 76-92.https://doi.org/10.1016/j.tra.2016.09.008

[7]. M. C. R. Lopez, Y. D. Wong, Children's active trips to school: a review and analysis, International Journal of Urban Sustainable Development, 9 (2017) 79-95. https://doi.org/10.1080/19463138.2016.1264405

[8]. A. Carver et al., How are the built environment and household travel characteristics associated with children's active transport in Melbourne, Australia?, Journal of Transport \& Health, 12 (2019) 115-129. https://doi.org/10.1016/j.jth.2019.01.003

[9]. K. Y. K. Leung, B. P. Y. Loo, Determinants of children's active travel to school: A case study in Hong Kong, Travel Behaviour and Society, 21 (2020) 79-89. https://doi.org/10.1016/j.tbs.2020.05.009 [10]. A. Siiba, Active travel to school: Understanding the Ghanaian context of the underlying driving factors and the implications for transport planning, Journal of Transport \& Health, 18 (2020) 100869. https://doi.org/10.1016/j.jth.2020.100869

[11]. D. Pojani, K. Boussauw, Keep the children walking: active school travel in Tirana, Albania, Journal of Transport Geography, 38 (2014) 55-65. https://doi.org/10.1016/j.jtrangeo.2014.05.012

[12]. N. Singh, V. Vasudevan, Understanding school trip mode choice - The case of Kanpur (India), Journal of Transport Geography, 66 (2018) 283-290. https://doi.org/10.1016/j.jtrangeo.2017.12.007

[13]. I. N. Sener et al., An examination of children's school travel: A focus on active travel and parental effects, Transportation Research Part A: Policy and Practice, 123 (2019) 24-34. https://doi.org/10.1016/j.tra.2018.05.023

[14]. A. K. Yarlagadda, S. Srinivasan, Modeling children's school travel mode and parental escort decisions, Transportation, 35 (2008) 201-218. https://doi.org/10.1007/s11116-007-9144-6

[15]. WHO, Timeline: WHO's 2020. https://www.who.int/emergencies/diseases/novel-coronavirus-2019/interactive-timeline (accessed Oct. 01, 2020). 
Transport and Communications Science Journal, Vol. 72, Issue 7 (09/2021), 778-788

[16]. J. De Vos, The effect of COVID-19 and subsequent social distancing on travel behavior, Transportation Research Interdisciplinary Perspectives, 5 (2020) 100121. https://doi.org/10.1016/j.trip.2020.100121

[17]. S. J. Barnes, Information management research and practice in the post-COVID-19 world, $\begin{array}{lllllll}\text { International Journal of Information Management, } 55 & \text { (2020) } & 102175 .\end{array}$ https://doi.org/10.1016/j.ijinfomgt.2020.102175

[18]. UNICEF, What will a return to school during COVID-19 look like?, 2020. https://www.unicef.org/coronavirus/what-will-return-school-during-covid-19-pandemic-look

(accessed Oct. 01, 2020).

[19]. CNN, How Vietnam managed to keep its coronavirus death toll at zero, 2020. https://edition.cnn.com/2020/05/29/asia/coronavirus-vietnam-intl-hnk/index.html

[20]. M. H. Nguyen, Factors influencing home-based telework in Hanoi (Vietnam) during and after the COVID-19 era, Transportation, (2021). https://doi.org/10.1007/s11116-021-10169-5.

[21]. T. V. Nguyen et al., In the interest of public safety: rapid response to the COVID-19 epidemic in Vietnam, BMJ Global Health, 6.1 (2021) e004100. https://doi.org/10.1136/bmjgh-2020-004100.

[22]. UNICEF, COVID-19 and School Closures: One year of education disruption, (2021) [Online]. Available: https://data.unicef.org/resources/one-year-of-covid-19-and-school-closures/

[23]. A. Leung, T. P. L. Le, Factors associated with adolescent active travel: A perceptive and mobility culture approach - Insights from Ho Chi Minh City, Vietnam, Transportation Research Part A: Policy and Practice, 123 (2019) 54-67.https://doi.org/10.1016/j.tra.2018.09.004

[24]. N. H. H. D. Trang et al., Active Commuting to School Among Adolescents in Ho Chi Minh City, Vietnam: Change and Predictors in a Longitudinal Study, 2004 to 2009, American Journal of Preventive Medicine, 42 (2012) 120-128. https://doi.org/10.1016/j.amepre.2011.10.006

[25]. S. Li, P. Zhao, The determinants of commuting mode choice among school children in Beijing, Journal of Transport Geography, 46 (2015) 112-121. https://doi.org/10.1016/j.jtrangeo.2015.06.010

[26]. N. C. McDonald, Children's mode choice for the school trip: the role of distance and school location in walking to school, Transportation, 35 (2008) 23-35. https://doi.org/10.1007/s11116-0079135-7

[27]. D. T. Huynh, J. Gomez-Ibañez, Vietnam, in The Urban Transport Crisis in Emerging Economies, D. Pojani and D. Stead, Eds. Cham: Springer International Publishing, (2017) 267-282.

[28]. D. Huynh, Making Megacities in Asia: Comparing National Economic Development Trajectories. Singapore: Springer Singapore, 2020.

[29]. M. H. Nguyen et al., Impediments to the bus rapid transit implementation in developing countries - a typical evidence from Hanoi, International Journal of Urban Sciences, 23 (2019) 464483. https://doi.org/10.1080/12265934.2019.1577747

[30]. M. H. Nguyen, D. Pojani, Why Do Some BRT Systems in the Global South Fail to Perform Or Expand?, in Preparing for the New Era of Transport Policies: Learning from Experience, First., vol. 1, Y. Shiftan and M. Kamargianni, Eds. ELSEVIER ACADEMIC PRESS, (2018) 35-61.

[31]. D. Potoglou and B. Arslangulova, Factors influencing active travel to primary and secondary schools in Wales, Transportation Planning and Technology, 40 (2017) 80-99. https://doi.org/10.1080/03081060.2016.1238573.

[32]. M. Ben-Akiva, S. R. Lerman, Discrete Choice Analysis: Theory and Application to Travel Demand, 1st Edition. Cambridge, Mass: The MIT Press, 1985.

[33]. R. M. O'brien, A Caution Regarding Rules of Thumb for Variance Inflation Factors, Qual Quant, 41 (2007) 673-690. https://doi.org/10.1007/s11135-006-9018-6

[34]. OECD, OECD Urban Policy Reviews: Viet Nam. OECD Publishing, 2018. 